\title{
Inflammatory carcinoma of breast in a post menopausal woman - a case report
}

\author{
Pranav Kumar Dave, S Khan, V Agarwal, Vivek Gupta, R Mishra, M Puranik, \\ M Jain, P Chouhan, P Gupta, A Patidar
}

\begin{abstract}
Corresponding author: Dr. Pranav Kumar Dave, Associate Professor, Department of Radiology, L N Medical College and J K Hospital, Kolar Road, Bhopal, MP, India;

Email : pranavkdave@rediffmail.com
\end{abstract}

Distributed under Attribution-Non Commercial - Share Alike 4.0 International (CC BY-NC-SA 4.0)

\begin{abstract}
Inflammatory breast carcinoma (IBC) is uncommon, aggressive form of primary breast cancer due to its rapid proliferation. Diagnosis is made on clinical, cytology and histology correlation. Imaging is performed to look for the extent of disease. Breast ultrasound and mammography are common modalities performed for primary lesion detection, local progression of disease and for monitoring of treatment.
\end{abstract}

Keywords: Inflammatory breast cancer, carcinoma mastitis, infective mastitis, breast ultrasound, mammography.

Inflammatory breast carcinoma (IBC) is also known as carcinoma mastitis (CM) and represents the most virulent form of breast cancer. It is an uncommon and aggressive form of breast cancer with inflammatory skin changes ${ }^{1}$. Usually presents in women between the $4^{\text {th }}$ and $5^{\text {th }}$ decades. The first description of IBC / CM in the scientific literature was published in 1814 by Sir Charles Bell ${ }^{2}$, and then in 1938 the terms "True IBC" and "Primary IBC" were coined to distinguish "IBC" and "secondary IBC". Secondary IBC was defined by secondary changes in the breast or recurrence of breast cancer ${ }^{3}$. The incidence of IBC varies in different regions of the world. More common in North Africa, 5-7\% of all breast cancer in Tunisia ${ }^{4}, 4-5 \%$ in Morocco ${ }^{5}$, while in Egypt it has a rate of $11 \%{ }^{6}$.

Data for IBC from India are limited. The median age was reported as 45 years with a range 23-66years and median duration of symptom was 5 months. IBC is characterized by its rapid progression and higher potential of metastasis ${ }^{7}$. Diagnosis of this entity is essentially clinical and histological. Multidisciplinary modality approach of imaging surgery and chemotherapy is required to diagnose and for treatment of IBC. The 5-year survival of patients with this cancer type is low compared to other breast cancers ${ }^{4}$.

Case

A 61 years old post menopausal female was referred to the radiology department for mammography and breast ultrasound. She was complaining of swelling and redness in right breast with retraction right nipple since 2 months. On examination, overlying skin appeared red with retracted right nipple (figure 1).

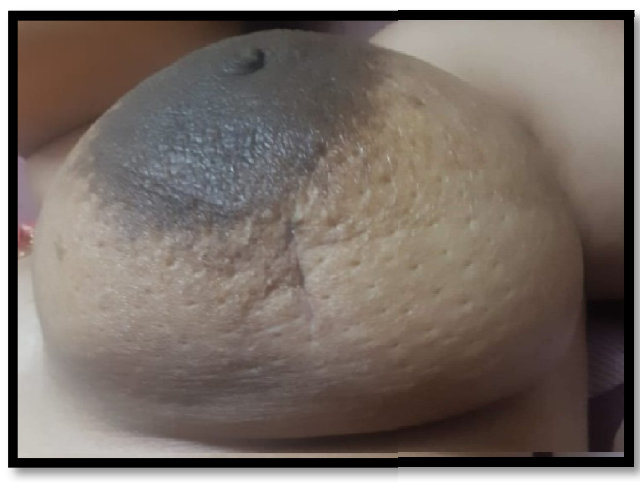

Figure 1: Clinical photograph of inflammatory changes

Received: $27^{\text {th }}$ July 2020, Peer review completed: $30^{\text {th }}$ September 2020, Accepted: $5^{\text {th }}$ January 2021.

Dave PK, Khan S, Agarwal V, Gupta V, Mishra R, Puranik M, et al. Inflammatory carcinoma of breast in a post menopausal woman - a case report. The New Indian Journal of OBGYN. 2021; 8(1): 135-38. 
On palpation, swelling was warm, tender and edematous. A lump was palpable in outer upper quadrant of right breast, which was adherent to skin but not to underlying muscle. No palpable axillary lymph nodes noted. Other system examination was within normal limits. There was no positive family history of breast cancer in her family. Her personal history was insignificant. Skiagram chest and ultrasound abdomen and pelvis were normal. Her breast ultrasound revealed - poorly defined heterogeneous hypoechoic mass lesion with microlobulated margins causing posterior acoustic shadowing in upper outer quadrant of right breast (figure 2). Lesion was non parallel in orientation with diffuse skin thickening of more than $3 \mathrm{~mm}$. Increased vascularity of lesion was seen on color doppler.

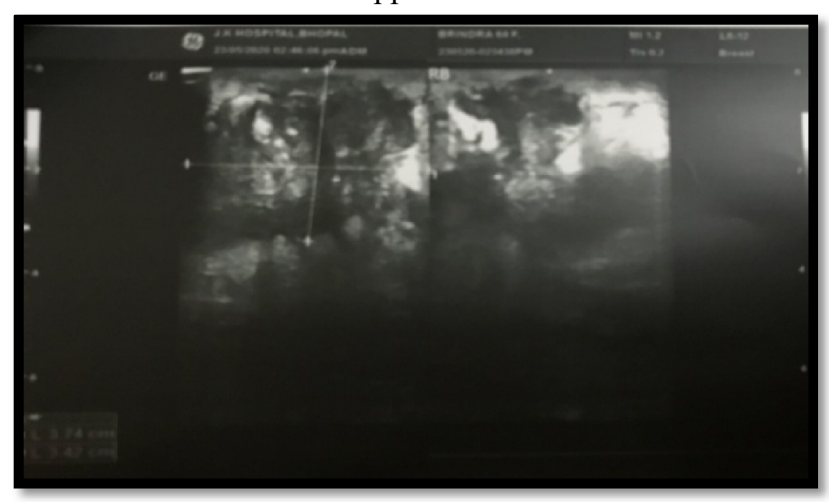

Figure 2: Right breast ultrasound poorly defined heterogenous hypoechoic mass lesion

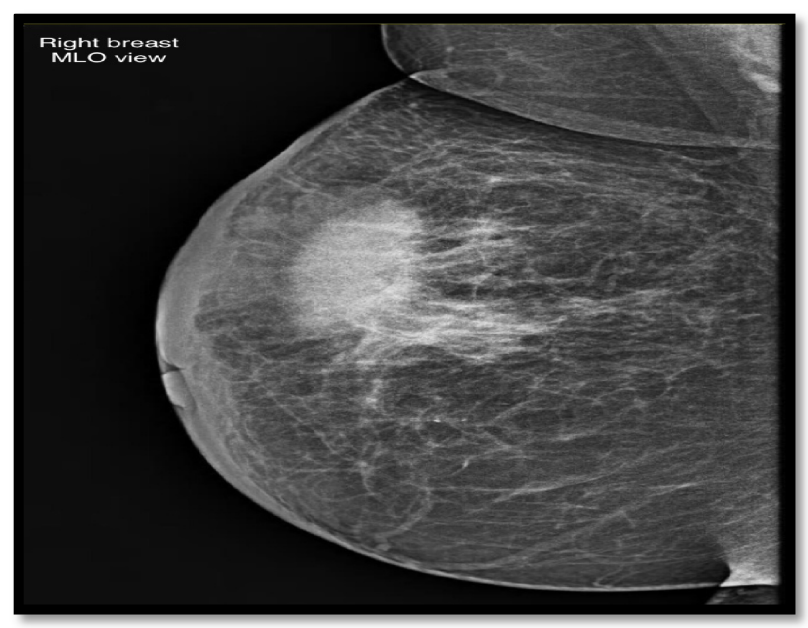

Figure 3: Right Mammo MLO view - focal dense with spiculated margins with few scattered microcalcification, retraction of nipple with skin and subcutaneous tissue thickening.

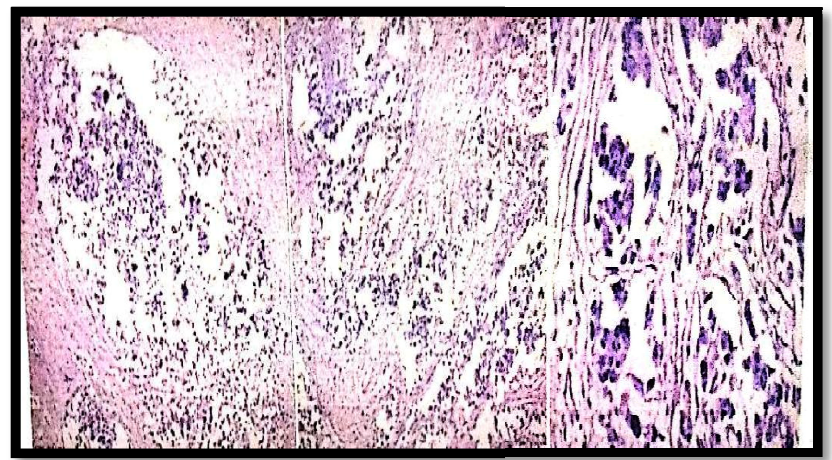

Figure 4: Invasive ductal carcinoma grade II

Subcutaneous tissue oedema was seen in adjacent to and surrounding to the focal lesion. Mammogram of right breast revealed an ill defined dense lesion in upper outer quadrant with spiculated margins and few scattered micro calcification (figure 3). Nipple was retracted with thickening of adjacent skin and subcutaneous tissue. Opposite breast and axillary region were normal on mammography. USG guided aspiration cytology from right breast mass lesion was suggestive of IBC (figure 4). Planned radical mastectomy for right beast was performed. Specimen histology confirmed invasive duct carcinoma grade II with no evidence of any involvement of lymph node. Nipple and areola were unremarkable. Skin and subcutaneous tissue were free.

\section{Discussion}

Inflammatory breast carcinoma is uncommon locally and aggressive breast cancer ${ }^{8}$. Its incidence is $1-4 \%$ of all breast cancers ${ }^{1}$ and commonly seen in females between $4^{\text {th }}$ to $5^{\text {th }}$ decades ${ }^{9}$. There are no established risk factors for IBC. However few suspected risk factors associated with IBC are black race, body mass index (BMI), age and region ${ }^{11}$.

Affected mostly in African American women have 50\% higher incidence than Caucasian ${ }^{8,10}$. The median age was reported as 45 years with a range 23-66 and median duration of symptom was 5 months ${ }^{12,13}$. Clinically, inflammatory breast cancer mimics mastitis ${ }^{9}$. IBC commonly presents with rapid progressive tenderness, warmth, and enlargement of involved breast, duration of history $<6$ months. Skin is erythematous, warmed, indurated as well as peaud'orange. Nipple retraction with axillary lymph nodes enlargement is commonly seen on affected side. The condition is not painful as compared to the alarming appearance on examination. Systemic symptoms do not include fever and patient does not respond to antibiotics ${ }^{8}$. These may help differentiate IBC 
The New Indian Journal of OBGYN. 2021 (July-December);8(1)

from IM. Currently there are no definitive molecular or pathological criteria for IBC diagnosis ${ }^{10}$. Histologically, IBC is uncommon type of invasive breast cancer. Invasive ductal carcinoma is the most common type of all primary breast cancer. Hence the diagnosis is entirely based on clinical symptoms like rapid onset of erythema and edema of breast skin, similar to any benign bacterial infection such as mastitis. IBC is not present with symptoms of infection like fever ${ }^{10,14}$. As per American Joint Committee on Cancer AJCC IBC diagnosis criteria are rapid onset of erythema occupying at least one-third of the breast, edema and or orange peel of the breast and / or a warm breast of initial presentation of 3 months ${ }^{10,15}$. Our patient also presented with swelling and redness of skin in right breast with retraction right nipple of 2 months duration. As such IBC is not considered as a specific histological sub type of breast carcinoma and has no specific diagnostic pathological features. Most IBC are ductal carcinoma with high nuclear grade $^{10}$. About 17 to $30 \%$ of IBC cases are triple negative and 18 to $44 \%$ are epidermal growth factor receptor 2 (HER 2) positive ${ }^{10}$. Usually with the characteristic clinical presentation and histopathological examination confirm the diagnosis of IBC. Dermal lymphatic emboli are seen in about $75 \%$ of cases. However no direct correlation seen in between the presence, number or size of emboli and the degree of redness of the skin in patients with $\mathrm{IBC}^{10}$. No evidence of involvement of skin, nipple areola and axillary lymph nodes were seen on excised MRM specimen of the case.

Advances in imaging techniques have improved the diagnosis of breast carcinoma, IBC and useful to monitor the response to treatment with screening of contra lateral breast ${ }^{15}$. Breast ultrasound provide valuable information for regional axillary and supraclavicular lymph node along with primary breast tumor skin and subcutaneous tissue status. Mammography is the current standard imaging although optimal compression can be limited by the pain related to breast's inflammation. Mammography can reveal skin thickening, stromal infiltration, architectural distortion and or diffuse increase in density. The tumor mass is absent in $25 \%$ of IBC. There was focal mass lesion with architectural disorganization and surrounding skin thickening with nipple retraction was noted in our case. Distant metastases noted in $20-30 \%$ of newly diagnosed IBC cases ${ }^{10}$. Post operative, Chemotherapy was given to her. There was no evidence of distant metastasis during the initial stage and on subsequent follow up to 6 months during post operative period.

\section{Conclusion}

Breast cancer is one of the most common cancer found in Indian women. IBC is very virulent verity of breast cancer. Common presentation is seen in both IBC and mastitis. Our case of IBC was presented in a post menopausal women with a history of short duration. A clinical suspicion of IBC was confirmed on imaging and cytology. Finally histopathology reconfirmed the diagnosis of IBC.

\section{Conflict of interest: None. Disclaimer: Nil.}

\section{References}

1. Hance KW, Anderson WF, Devesa SS, Young HA, Levine PH. Trends in inflammatory breast carcinoma incidence and survival: the surveillance, epidemiology, and end results program at the National Cancer Institute. J Natl Cancer Inst. 2005 Jul 6; 97(13): 966-75.

2. Cristofanilli M, Buzdar AU, Hortobágyi GN. Update on the management of inflammatory breast cancer. Oncologist. 2003;8(2):141-8.

3. Taylor G, Meltzer A. Inflammatory carcinoma of the breast. Am J Cancer. 1977; 33 (1938): 33-49.

4. Boussen H, Bouzaiene H, Ben Hassouna J, Gamoudi A, Benna F, Rahal K. Inflammatory breast cancer in Tunisia: reassessment of incidence and clinicopathological features. Semin Oncol. 2008 Feb; 35(1): 17-24.

5. Slaoui M, Zoure AA, Mouh FZ, et al. Outcome of inflammatory breast cancer in Moroccan patients: clinical, molecular and pathological characteristics of 219 cases from the National Oncology Institute (INO). BMC Cancer. 2018 Jul;18(1):713.

6. Soliman AS, Banerjee M, Lo AC, et al. High proportion of inflammatory breast cancer in the Population-based Cancer Registry of Gharbiah, Egypt. Breast J. 2009;15(4):432-434.

7. Cristofanilli M, Buzdar AU, Hortobágyi GN. Update on the management of inflammatory breast cancer. Oncologist. 2003;8(2):141-8.

8. Levit A, Voci SL. Inlfammatory Breast Carcinoma. Ultrasound quarterly. 2013; 29(3): 223-4.

9. Thurston M, Radswiki. Inflammatory carcinoma of the breast. Radiopaedia. Available from: https://radiopaedia. org/articles/modic-type-endplate-changes

10. Mamouch F, Berrada N, Aoullay Z, El Khanoussi B, Errihani H. Inflammatory Breast Cancer: A Literature Review. World J Oncol. 2018; 9(5-6):129-35. 
11. Dushkin H, Cristofanilli M. Inflammatory breast cancer. J Natl Compr Canc Netw. 2011 Feb;9(2):233-40.

12. Gogia A, Deo SV, Shukla NK, Mathur S, Sharma DN, Tiwari A. Clinicopathological profile of breast cancer: An institutional experience. Indian J Cancer. 2018 JulSep;55(3):210-3.

13. Gogia A, Raina V, Deo SV, Shukla NK, Mohanti BK, Sharma DN. Inflammatory breast cancer: a single centre analysis. Asian Pac J Cancer Prev. 2014;15(7): 3207-10.

14. Ellis DL, Teitelbaum SL. Inflammatory carcinoma of the breast. A pathologic definition. Cancer. 1974 Apr; 33(4):1045-1047.

15. Yang WT, Le-Petross HT, Macapinlac H, Carkaci S, Gonzalez-Angulo AM, Dawood S, et al. Inflammatory breast cancer: PET/CT, MRI, mammography, and sonography findings. Breast Cancer Res Treat. 2008 Jun;109(3):417-26.

Pranav Kumar Dave ${ }^{1}$, S Khan ${ }^{2}$, V Agarwal $^{3}$, Vivek Gupta $^{4}, \mathrm{R}_{\text {Mishra }}{ }^{5}, \mathrm{M}$ Puranik ${ }^{6}, \mathrm{M}$ Jain ${ }^{7}, \mathrm{P}$ Chouhan ${ }^{8}$, P Gupta ${ }^{9}$, A Patidar ${ }^{10}$
${ }^{1}$ Associate Professor, Department of Radiology, L N Medical College and J K Hospital, Kolar Road, Bhopal, MP, India; ${ }^{2}$ Associate Professor, Department of Surgery, L N Medical College and J K Hospital, Kolar Road, Bhopal, MP, India; ${ }^{3}$ Professor, Department of Pathology, L N Medical College and J K Hospital, Kolar Road, Bhopal, MP, India; ${ }^{4}$ Professor, Department of Radiology, L N Medical College and J K Hospital, Kolar Road, Bhopal, MP, India; ${ }^{5}$ Professor, Department of Radiology, L N Medical College and J K Hospital, Kolar Road, Bhopal, MP, India; ${ }^{6}$ Assistant Professor, Department of Radiology, L N Medical College and J K Hospital, Kolar Road, Bhopal, MP, India; ${ }^{7}$ Professor and HOD, Department of Radiology, L N Medical College and J K Hospital, Kolar Road, Bhopal, MP, India; ${ }^{8}$ Resident, Department of Radiology, L N Medical College and J K Hospital, Kolar Road, Bhopal, MP, India; ${ }^{9}$ Resident, Department of Radiology, L N Medical College and J K Hospital, Kolar Road, Bhopal, MP, India; ${ }^{10}$ Resident, Department of Radiology, L N Medical College and J K Hospital, Kolar Road, Bhopal, $\mathrm{MP}$, India 